\title{
Expression of alternansucrase in potato plants
}

\author{
Géraldine A. Kok-Jacon · Jean-Paul Vincken - Luc C. J. M. Suurs • \\ Denong Wang · Shaoyi Liu · Richard G. F. Visser
}

Received: 14 February 2007 / Accepted: 19 February 2007 / Published online: 23 March 2007

(C) Springer Science+Business Media B.V. 2007

\begin{abstract}
Alternan, which consists of alternating $\alpha-(1 \rightarrow 3) / \alpha-(1 \rightarrow 6)$-linked glucosyl residues, was produced in potato tubers by expressing a mature alternansucrase (Asr) gene from Leuconostoc mesenteroides NRRL B-1355 in potato. Detection of alternan was performed by enzyme-linked immunosorbent assay in tuber juices, revealing a concentration between 0.3 and $1.2 \mathrm{mg} \mathrm{g}^{-1}$ fresh
\end{abstract}

G. A. Kok-Jacon · J.-P. Vincken .

L. C. J. M. Suurs · R. G. F. Visser ( $\square)$

Graduate School Experimental Plant Sciences,

Laboratory of Plant Breeding, Wageningen

University, P.O. Box 386, 6700 AJ Wageningen

The Netherlands

e-mail: richard.visser@wur.nl

D. Wang

Departments of Genetics, Neurology and

Neurological Sciences, Stanford University School of

Medicine, Beckman Center B006, Stanford

CA 94305-5318, USA

D. Wang $\cdot$ S. Liu

Functional Genomics Division, Columbia Genome

Center, College of Physicians and Surgeons,

Columbia University, 1150 St. Nicholas Avenue,

New York, NY 10032, USA

Present Address:

G. A. Kok-Jacon

Laboratory of Tropical Crop Improvement,

Katholieke Universiteit Leuven, Kasteelpark

Arenberg 13, 3001 Leuven, Belgium wt. The Asr transcript levels correlated well with alternan accumulation in tuber juices. It appeared that the expression of sucrose-regulated starchsynthesizing genes (ADP-glucose pyrophosphorylase subunit $\mathrm{S}$ and granule-bound starch synthase I) was down-regulated. Despite this, the physicochemical properties of the transgenic starches were unaltered. These results are compared to those obtained with other transgenic potato plants producing mutan $[\alpha-(1 \rightarrow 3)$-linked glucosyl residues] and dextran $[\alpha-(1 \rightarrow 6)$-linked glucosyl residues].

Keywords Alternan - Glucansucrase - Polymer solubility $\cdot$ Transgenic potato

\section{Introduction}

Production of novel polymers in plants by genetic modification is a great opportunity to obtain plants with unique properties that cannot be generated by conventional breeding (Kok-Jacon et al. 2003). In addition, modifications of native polymers in planta could also generate crops with added nutritional, environmental or commercial value. For instance, production of biodegradable plastics in crops such as flax offers new perspectives for the replacement of oil-derived plastics (Wróbel et al. 2004). Another example is the production of a freeze-thaw-stable potato starch 
exhibiting novel physicochemical properties, thereby increasing the number of industrial applications (Jobling et al. 2002).

Alternan is a unique polymer which is produced by three Leuconostoc mesenteroides strains: NRRL B-1355, NRRL B-1498 and NRRL B-1501 (Jeanes et al. 1954). Alternan synthesized by $L$. mesenteroides NRRL B-1355 is mediated by the alternansucrase ASR (EC 2.4.1.140) which is a large glucansucrase of 2,057 amino-acids (Argüello-Morales et al. 2000). Its $C$-terminal domain (also referred to as glucan-binding domain or GBD) exhibits short repeats specific for ASR, which could contribute to its distinct features (Janeček et al. 2000). The resulting polymer has a unique structure with alternating $\alpha-(1 \rightarrow 3) / \alpha-(1 \rightarrow 6)$-linked glucose residues, present for $46 \%$ and $54 \%$, respectively. Due to this structure, alternan is a highly soluble and low viscous polymer, which is resistant to microbial and mammalian enzymes making it suitable for the production of ingredients for functional foods such as prebiotics (Côté 1992). Also, novel industrial applications were investigated by hydrolyzing native alternan polymers with isolates of Penicillium bacterial strains, creating potential replacers of commercial gum arabic (Leathers et al. 2002; 2003). Furthermore, ASR is an attractive enzyme because of its efficiency in bond formation, which is higher than that of the dextransucrase (DSRS) (Richard et al. 2003). In addition, mutated ASR enzymes showed a high efficiency in glucosylating acceptor molecules (cellobiose, $\alpha$-alkylglucosides) in comparison to native ASR and DSRS enzymes, which might enable novel industrial applications (ArgüelloMorales et al. 2001; Richard et al. 2003; Luz Sanz et al. 2006).

In this work, we describe the production of alternan in potato tubers by expressing ASR. Modification of starch structure was envisaged with ASR, because of its high acceptor reaction efficiency. The effect of ASR on starch biosynthesis was studied at the microscopical, molecular and biochemical level, and compared to the effects of the dextransucrase (DSRS) and mutansucrase (GTFI), producing less soluble polymers, such as dextran and mutan that are mainly composed of $\alpha-(1 \rightarrow 6)$ and $\alpha-(1 \rightarrow 3)$-linked glucose residues, respectively (Kok-Jacon et al. 2005a, b).

\section{Materials and methods}

Construction of binary plant expression vector containing the Asr gene

An expression cassette containing the patatin promoter (Wenzler et al. 1989), the chloroplastic ferredoxin signal peptide (FD) from Silene pratensis (Pilon et al. 1995) fused to the NOS terminator was cloned into the pBluescript SK (pBS $\mathrm{SK}$ ) plasmid, resulting in $\mathrm{pPF}$ that was used as starting material for cloning the alternansucrase (Asr) gene. A mature Asr gene from L. mesenteroides NRRL B-1355 (Argüello-Morales et al. 2000; AJ250173) was ligated in frame between the signal peptide FD and the NOS terminator. The mature Asr gene was amplified by PCR, with a forward primer containing a $S m a$ I restriction site (5'-CATCAGGGCCCCGGGGATACAAAT-3') and a reverse primer containing a $\mathrm{NruI}$ restriction site (5'-CTCCTTTCGCGAATCCTTCCCTTA$\left.3^{\prime}\right)$ using the proofreading $P f u$ turbo DNA polymerase (2.5 units/ $\mu \mathrm{l}$; Stratagene, UK) and cloned into the SmaI/NruI restriction sites of $\mathrm{pPF}$, resulting in pPFAsr. FD and the fused Asr gene were completely sequenced in one direction by Baseclear (The Netherlands) to verify the correctness of the construct. pPFAsr was digested with $S a c I$ and $S a l I$ and subsequently ligated into a pBIN20 binary vector (Hennegan and Danna 1998), resulting in pPFA (Fig. 1).
Fig. 1 Schematic representation of pPFA binary vector used for potato plant transformation

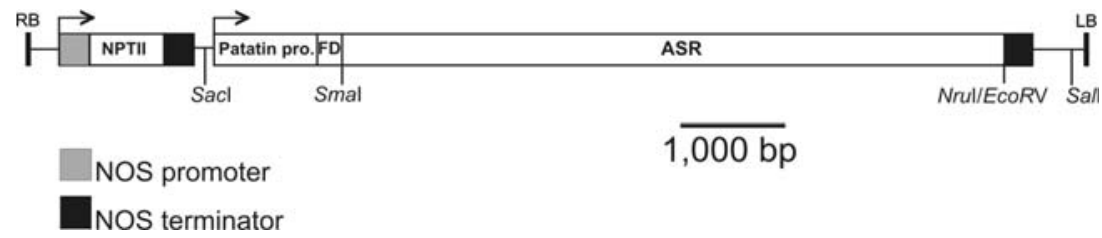


Transformation and regeneration of potato plants

pPFA was transformed into Agrobacterium tumefaciens strain LBA 4404 using electroporation (Takken et al. 2000). Internodal stem segments from the tetraploid potato genotype (cv. Kardal (KD)) were used for Agrobacterium-mediated transformation, which was performed as described by Kok-Jacon et al. (2005a).

Starch isolation

Potato tubers were peeled and homogenized in a Sanamat Rotor (Spangenberg, The Netherlands). The resulting homogenate was allowed to settle overnight at $4^{\circ} \mathrm{C}$ and the potato juice was decanted and stored at $-20^{\circ} \mathrm{C}$ for characterization of soluble alternan. The starch pellet was washed three times with water, air-dried at room temperature for at least three days and stored at room temperature.

Immunological detection of alternans in tuber juices and gelatinized starches

Presence of alternans was investigated with enzyme-linked immunosorbent assay (ELISA) as described by Kok-Jacon et al. (2005a), using monoclonal anti- $\alpha-(1 \rightarrow 6)$ dextran antibodies (45.21.1 (groove-type; IgA/Kappa) and 16.4.12 $\mathrm{E}^{\mathrm{BI}}$ (cavity-type; IgA/Kappa)) (Wang et al. 2002) with tuber juices and gelatinized starches. The monoclonal anti- $\alpha-(1 \rightarrow 6)$ dextran antibodies detect structures containing both internal and terminal epitopes of $\alpha-(1 \rightarrow 6)$ dextran which can be applicable for the detection of $\alpha-(1 \rightarrow 6)$ linked glucose residues present in alternan (Sharon et al. 1982; Dr Denong Wang, personal communication).

Expression analysis of $A s r$ and genes involved in starch biosynthesis using semi-quantitative and real-time quantitative RT-PCR analysis

RNA was isolated from $3 \mathrm{~g}$ (fresh weight) of potato tuber material from selected transgenic lines according to Kuipers et al. (1994).

Semi-quantitative and real-time quantitative RT-PCR's were performed as described by
Kok-Jacon et al. (2005a). AsrRT primers, 5'ACCGGTTCCATCAACTAATAAT-3' and $5^{\prime}$ GACATCTCGGAAGGATCCC- $3^{\prime}\left(\mathrm{Tm}=55^{\circ} \mathrm{C}\right.$, 35 cycles) were based on the $A s r$ gene sequence (Argüello-Morales et al. 2000). RNA sample from Karnico potato tubers expressing a sense/ antisense GBSSI cDNA inverted-repeat construct referred to as RVT34-77 (Heilersig 2005) was used as a positive control, because its GBSSI expression level was completely down-regulated.

Determination of morphological and physicochemical starch properties

Analysis of starch granule morphology was performed by light microscopy and scanning electron microscopy (SEM) as described by Kok-Jacon et al. (2005a).

Median values of the granule size distribution $\left(\mathrm{d}_{50}\right)$, gelatinization analysis, amylose content, starch content, chain length distributions (HPSEC, HPAEC) were determined as described by Kok-Jacon et al. (2005a).

\section{Results}

Detection of alternan in transgenic potato juices

To enable plastidic protein targeting, the mature Asr gene was fused to the ferredoxin (FD) signal peptide (Gerrits et al. 2001). The resulting gene fusion was inserted between the patatin promoter (Fig. 1) allowing high-tuber expression (Wenzler et al. 1989) and the Nos terminator sequence. At the FD $\mathbf{\Delta} A s r$ fusion, two mutations were present because a $S m a$ I restriction site was engineered at this position $\quad(\mathrm{VTAM} \downarrow$ ATYKVTLITK $\mathbf{A D T}$ became VTAM $\downarrow$ ATYKVTLITP $\mathbf{A}$ GT, in which $\downarrow$ represents the splice site for amyloplast entry and $\boldsymbol{\Delta}$ the gene fusion). Furthermore, differences from the published ASR sequence (ArgüelloMorales et al. 2000) were found at three positions $\left(\mathrm{Y}_{208} \mathbf{H}, \mathrm{D}_{221} \mathbf{G}\right.$ and $\left.\mathrm{G}_{1092} \mathbf{S}\right)$, but these did not affect conserved residues. After Agrobacteriummediated plant transformation, thirty independent transgenic potato clones were obtained using 
the Kardal (KD) genotype. Five plants of each transgenic clone were grown in the greenhouse from which the tubers were pooled for further characterization. KDAxx referred to the transformed potato plant serie in which A represents the Asr gene and $\mathrm{xx}$ the clone number. The untransformed genotype is referred to as KD-UT.

Detection of alternan was performed by analyzing tuber juices of the transformants with ELISA using anti-dextran antibodies (Wang et al. 2002). Alternan was detected in 4 out of 29 tubers (about 14\%) in a concentration ranging from 0.3 to $1.2 \mathrm{mg} \mathrm{g}^{-1}$ fresh wt (Fig. 2) in the transformants KDA16, KDA19, KDA27 and KDA13. As expected, no alternan was found in KD-UT plants. According to the tuber juice results, the KDA transformants were divided in three classes: $(-),(+)$ and $(++)$, representing no, intermediate $\left(\leq 1 \mathrm{mg} \mathrm{g}^{-1} \mathrm{FW}\right)$ and high $\left(>1 \mathrm{mg} \mathrm{g}^{-1} \mathrm{FW}\right)$ levels of alternan, respectively. All the transformants containing alternan and two from the (-) class were selected for further characterization: KDA13 (++), KDA16 (+), KDA19 (+), KDA27 $(+)$, KDA1 (-) and KDA24 (-). RNA was isolated from potato tubers and subjected to RT-PCR analysis. The expression levels were determined for the Asr and Ubi3 genes, of which the latter is used as a control because of its constitutive expression (Garbarino and Belknap 1994) (Fig. 3). Heterologous Asr gene expression was detected in the expressers KDA13, KDA16, KDA19, KDA27. No Asr mRNA was detected in the (-) class transformants and in the KD-UT plants. The Asr expression levels correlated well with the ELISA results described above.

Alternan accumulation does not interfere with plant, tuber and starch morphologies

Asr expressing plants (green parts and tubers) did not exhibit any morphological changes in comparison to KD-UT plants (data not shown). In addition, starch morphology of Asr expressing plants was quite similar to that of KD-UT. With SEM, a rough surface was present on some of the $(++)$ class transformant granules (Fig. 4B, F), but was considered as not significant when compared to dextran- (Fig. 4C, G) and mutan- (Fig. 4D, H)

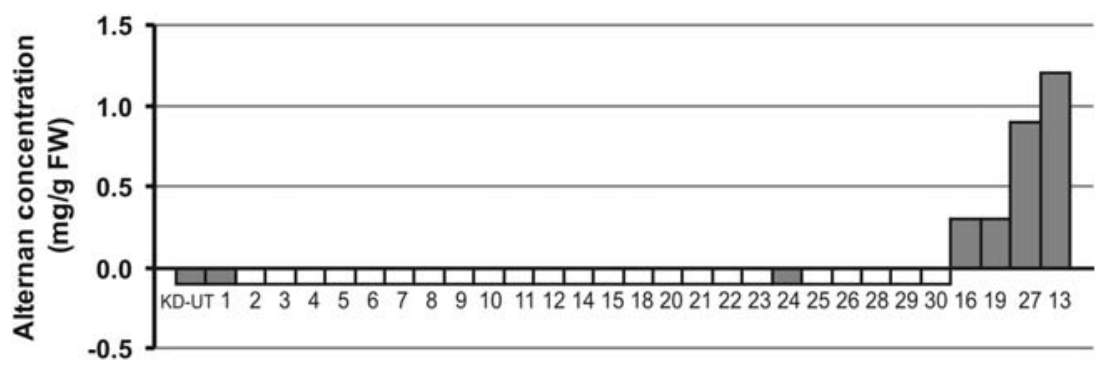

Transformant no.

Fig. 2 Detection of alternans accumulated in potato juices by ELISA using anti-dextrans antibodies. Based on the alternan concentration [in $\mathrm{mg} \mathrm{g}^{-1}$ fresh wt $\left.(\mathrm{FW})\right]$, three categories of transformants were made, where $(-),(+)$ and
$(++)$ represent no, intermediate and high alternan accumulation, respectively. Transgenic clones indicated with grey bars were selected for further characterization

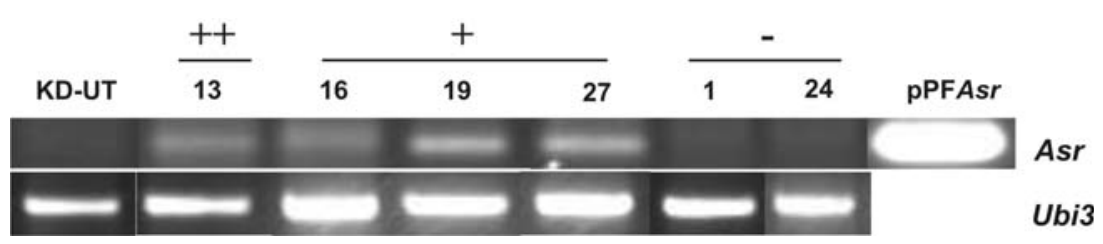

Fig. 3 RT-PCR analysis of the selected KDA transformants and KD-UT tuber RNA. The upper panel shows the PCR products using the primers designed on the Asr sequence. The lower panel shows the PCR products using the primers designed on the Ubi3 sequence that served as an internal control. pPFAsr plasmid: positive control 


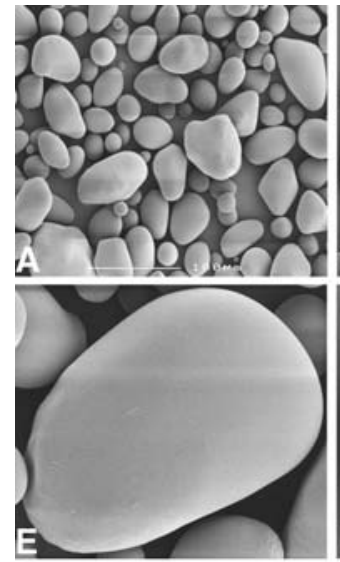

Ethanol precipitation (\%):

Altered granules (\%):

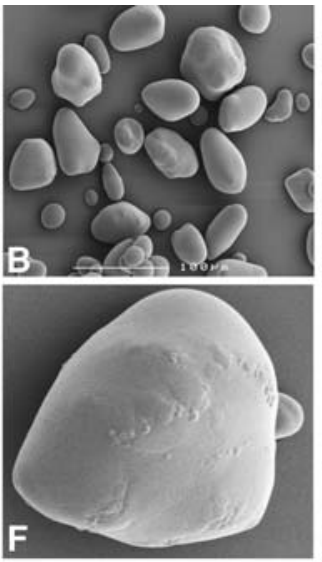

$40-44$

$12.0+/-1.0$

Fig. 4 SEM analysis of starch granules $(\times 350$ : upper panel) and $(\times 1,000$ : lower panel) from KD-UT $(\mathbf{A}, \mathbf{E})$ compared to that of selected transformants producing foreign polymers with decreasing water-solubility (KDA13 that produces alternan (B and $\mathbf{F}$; ++: highly soluble $(\mathrm{S})$ ), KDD30 that produces dextran (C and $\mathbf{G}$; +: soluble (L))

accumulating plants. In general, starch granules from the $(+)$ and $(-)$ class transformants were similar to those of the KD-UT (data not shown). Starch granules comparable to those illustrated in Fig. 4(F) were scored by analyzing a population of 100 granules in triplicate for each selected transformant (data not shown). KDA13, belonging to the $(++)$ class transformant, exhibited $(12 \% \pm 1.0)$ of altered starch granules, followed by the $(+)$ class transformant [KDA19 $(9.3 \% \pm 0.6)$; KDA27 $(8.3 \% \pm 0.6)]$. For the $(-)$ class transformant and KD-UT, the frequency of altered granules was lower, which was around the $7 \%$.

The physicochemical properties and starch content of KDA transformants remain unchanged

Median granule size $\left(\mathrm{d}_{50}\right)$, gelatinization characteristics $\left(T_{0}\right.$ and $\Delta H$ ), amylose and starch content measurements were performed on selected transformants (Table 1). From these results, it can be seen that no consistent changes were detected for the different classes of transformants. Furthermore, chain length distribution experiments (HPSEC and HPAEC) were also done, particularly

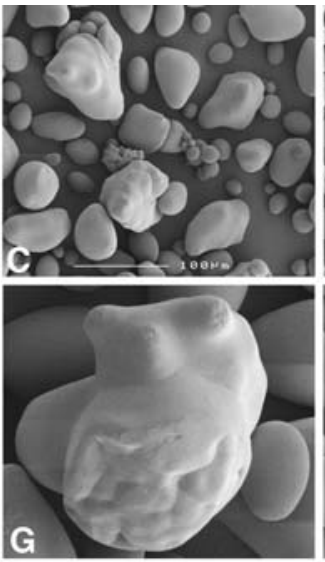

$34-37$

$16.0+/-1.0$

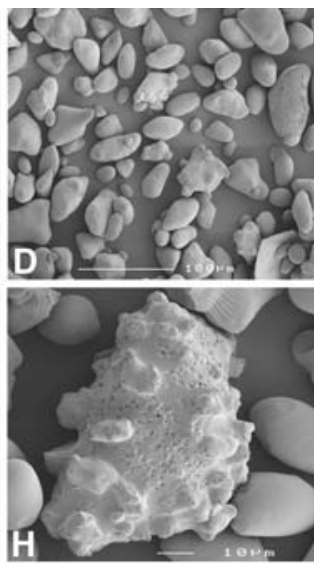

0

$31.3+/-2.3$ and KDIC15 that produces mutan (D and $\mathbf{H}$; -: insoluble (I)). Degrees of polymer solubility were defined according to Robyt (1996) in which class $\mathrm{S}=$ more soluble referring to glucans precipitated by $40-44 \%(\mathrm{v} / \mathrm{v})$ ethanol, $\mathrm{L}=1$ ess soluble referring to glucans precipitated by $34-37 \%$ ethanol and $\mathrm{I}=$ water-insoluble

because ASR exhibits a high acceptor reaction efficiency. After complete debranching of starch with isoamylase, no consistent changes were found with HPSEC and HPAEC in comparison to KD-UT starches (data not shown). In addition, debranched starches, which were further treated with $\alpha$-amylase, were analyzed with HPAEC in order to detect the presence of novel structural elements on starch molecules such as alternating $\alpha-(1 \rightarrow 3) / \alpha-(1 \rightarrow 6)$ linkages. Again, no consistent changes were detected with HPAEC in comparison to KD-UT starches (data not shown).

Expression levels of AGPase and GBSSI genes are down-regulated in the $(+)$ and $(++)$ KDA class

The expression levels of key genes involved in starch biosynthesis such as sucrose synthase (SuSy), ADP-glucose pyrophosphorylase subunit S (AGPase), starch synthase III (SSIII), starch branching enzyme I (SBEI) and granule-bound starch synthase I (GBSSI) were monitored by real-time quantitative RT-PCR (Fig. 5). All these genes seemed to be down-regulated, particularly the AGPase and GBSSI genes. In most cases, the extent of AGPase and GBSSI down-regulation 
Table 1 Summary of granule size $\left(\mathrm{d}_{50}\right)$, gelatinization characteristics $\left(\mathrm{T}_{o}, \Delta H\right)$, amylose and starch content measurements of starches from the selected transformants and KD-UT. Data $( \pm \mathrm{SD})$ are the average of two or three independent measurements

\begin{tabular}{llllll}
\hline Transformants & $\mathrm{d}_{50}(\mu \mathrm{m})^{*}$ & $T_{0}\left({ }^{\circ} \mathrm{C}\right) \dagger$ & $\Delta H(\mathrm{~kJ} / \mathrm{g}) \dagger$ & Amylose content $(\%)$ & Starch content $(\mathrm{mg} / \mathrm{g}$ FW $)$ \\
\hline KD-UT & $26.5( \pm 0.3)$ & $67.9( \pm 0.1)$ & $14.5( \pm 0.1)$ & $22.3( \pm 0.2)$ & $214.8( \pm 117.5)$ \\
KDA1 (-) & $24.4( \pm 0.2)$ & $68.1( \pm 0.1)$ & $17.0( \pm 0.1)$ & $22.2( \pm 0.2)$ & $103.4( \pm 66.3)$ \\
KDA24 (-) & $25.0( \pm 0.2)$ & $68.0( \pm 0.1)$ & $16.3( \pm 1.2)$ & $21.3( \pm 0.4)$ & $86.7( \pm 41.9)$ \\
KDA16 (+) & $24.9( \pm 0.3)$ & $67.9( \pm 0.2)$ & $16.4( \pm 1.3)$ & $22.2( \pm 0.1)$ & $140.0( \pm 88.2)$ \\
KDA19 (+) & $27.9( \pm 0.2)$ & $67.7( \pm 0.0)$ & $15.2( \pm 0.1)$ & $23.0( \pm 0.2)$ & $137.1( \pm 38.2)$ \\
KDA27 (+) & $22.8( \pm 0.7)$ & $67.7( \pm 0.2)$ & $16.2( \pm 0.5)$ & $22.2( \pm 0.4)$ & $289.3( \pm 39.7)$ \\
KDA13 (++) & $24.0( \pm 0.1)$ & $67.8( \pm 0.1)$ & $16.0( \pm 0.7)$ & $22.2( \pm 0.5)$ & $107.2( \pm 49.4)$ \\
\hline
\end{tabular}

* Median value of the granule size distribution

$\dagger$ Temperature of onset of starch gelatinization

$\ddagger$ Enthalpy released

corresponded well with the amount of alternan that was accumulated in the potato tubers. However, AGPase down-regulation did not correlate with a reduction in starch content for the $(++)$ transformants $\left(107.2 \pm 49.4 \mathrm{mg} \mathrm{g}^{-1} \mathrm{FW}\right)$ when compared to KD-UT $\left(214.8 \pm 117.5 \mathrm{mg} \mathrm{g}^{-1} \mathrm{FW}\right)$. Concerning GBSSI, the down-regulation was about 20 times less than for the transformant

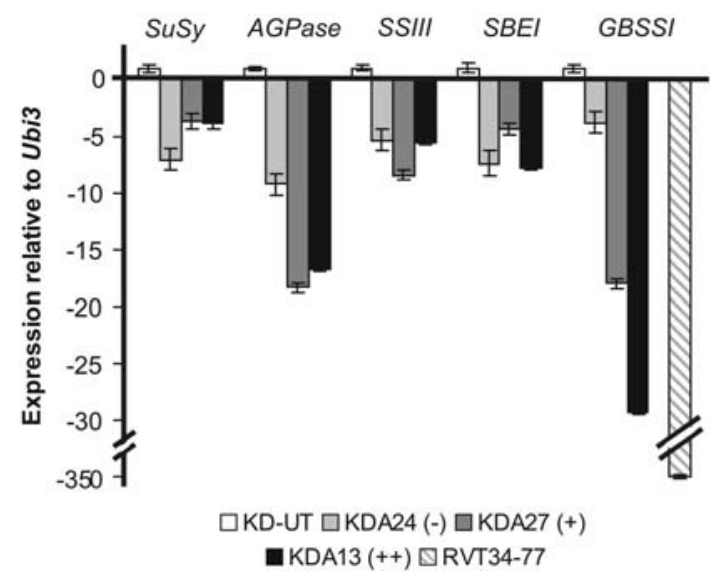

Fig. 5 Real-time quantitative RT-PCR analysis of KDA24 (-), KDA27 (+) and KDA13 (++) transformants and KD-UT tuber RNA using the following specific primers: $S u S y$, sucrose synthase; AGPase, ADP-glucose pyrophosphorylase subunit S; SSIII, starch synthase III; $S B E I$, starch branching enzyme I; GBSSI, granule-bound starch synthase I. RNA levels for each gene were expressed relative to the amount of Ubi3 RNA, as described in materials and methods. RNA sample from Karnico potato tubers expressing a sense/antisense $G B S S I$ cDNA construct exhibiting a complete GBSSI downregulation (RVT34-77), was used as a positive control
RVT34-77 in which GBSSI is completely inhibited. Typically, no reduction in amylose content was observed for the KDA transformants (Table 1), irrespective of their GBSSI messenger RNA level. Thus, the observed reduction in GBSSI expression for the (+) and (++) KDA classes were significant within the selected transformants, but relatively small with respect to the RVT34-77 transformant.

\section{Discussion}

This report is the first study on the production of alternan in potato tubers. Their presence in potato juices was demonstrated by ELISA using anti-dextran antibodies. Expression of ASR did not interfere with plant growth and development, and tuber and starch yield penalties were not observed. These results were similar to those obtained with the dextransucrase (DSRS) expression (Kok-Jacon et al. 2005a), but not to those obtained with the mutansucrase (GTFI) expression in which the tuber phenotype was significantly affected (Kok-Jacon et al. 2005b).

The amount of alternan accumulated in potato tubers $\left(1.2 \mathrm{mg} \mathrm{g}^{-1}\right.$ fresh wt) was lower than that of dextran $\left(1.7 \mathrm{mg} \mathrm{g}^{-1}\right.$ fresh wt) (KokJacon et al. 2005a). It might be possible that the large size of the mature ASR (2,057 amino-acids (a.a) when compared to DSRS with only 1,527 a.a.) might reduce the efficiency with which the enzyme is transported through the 
amyloplast membrane. However, such explanation needs to be approached with caution because the presence of alternansucrase in the amyloplast was not directly evidenced, as no ASR antibodies were available to us. Interestingly, it has been shown that the size of ASR can be reduced (by removal $82 \%$ (632/767 a.a.) of the C-terminal GBD) without compromising its activity (Joucla et al. 2006). If the size of the protein is indeed a critical factor, than this truncated variant may be a useful tool to enhance alternan synthesis in the amyloplast. Such an approach was already employed successfully for the Streptococcus downei mutansucrase GTFI (Kok-Jacon et al. 2005b). We have directed a mature and a GBD-truncated GTFI protein to potato amyloplasts, and found that the truncated form synthesized a larger amount of mutan, with much more pronounced effect on starch granule morphology.

Although ASR is known to be efficient in catalyzing acceptor reactions (Richard et al. 2003; Côté and Sheng 2006), no evidence was found for the covalent attachment of novel, alternan-based structural elements to starch molecules. Also with dextransucrase and mutansucrase we have not been able to introduce different glycosyl linkage patterns in starch (Kok-Jacon et al. 2005a, b). To this end, acceptor reactions of glucansucrases with starch or maltodextrins are not studied in much detail. It has been observed that the efficiency of acceptor reaction decreases with increasing length of maltodextrins (reviewed in Kok-Jacon et al. 2003). We had anticipated that the nascent starch polymers would be poor acceptors for the glucansucrases. However, during starch biosynthesis potential acceptors (small maltodextrins) are thought to be generated through the action of, for instance, debranching enzymes (or isoamylases). If such a small acceptor is mutanylated, alternanylated, or dextranylated at the non-reducing end, then these novel structures might be incorporated into starch polymers through the action of certain transferases such as, for instance, branching enzyme. Apparently, this does not happen, or at a very low (undetectable) frequency, but the reason for this is unclear.
Starch morphology in the ASR transformants was not significantly altered in comparison to that of dextran and mutan-accumulating plants (Fig. 4). This might be related to the fact that alternan is more water-soluble than dextran and mutan. An indication of the water-solubility of the three polysaccharides is given in Fig. 4; the more ethanol is required for precipitation, the higher the water-solubility. The water-solubility decreases in the order of alternan, dextran and mutan. We hypothesize that the co-synthesis of water-insoluble mutan and starch leads to cocrystallization of the two polymers, as a result of which the granule is packed in a less orderly fashion. This comparison should be approached with caution. For alternan and dextran, the observed differences in starch morphology may also be related to the fact that more dextran than alternan was accumulated in the potato tubers; for mutan, we have not been able to quantify the amount accumulated in the tubers. Therefore, it can not be excluded that the observed effects are related to the amount of foreign polymer produced. Interestingly, co-synthesis of levan, a water-soluble fructosyl-based polymer, and starch resulted in a dramatically altered starch granule morphology (Gerrits 2000). However, it should be noted that much higher levels of levan, which were estimated to be $66 \mathrm{mg} \mathrm{g}^{-1}$ fresh wt (Gerrits et al. 2001; Cairns 2003), were produced in comparison with alternan $\left(1.2 \mathrm{mg} \mathrm{g}^{-1}\right.$ fresh wt) or dextran (1.7 $\mathrm{mg} \mathrm{g}^{-1}$ fresh $\mathrm{wt}$ ), and that the starch granules contained approximately $5 \%$ of levan. This result contrasts with that of alternanand dextran-accumulating plants in which foreign polymers were only found in the stroma. Taking together the results of potato transformants expressing glucan- or levansucrases in amyloplasts, it seems that the site of accumulation of the foreign polymer (granule or stroma), the solubility of the foreign polymer, and the amount of foreign polymer that is actually produced are important factors in determining starch granule morphology.

Acknowledgements We would like to thank Isolde Pereira for her assistance with the tissue culture, Dirkjan Huigen for helping with the growth of the plants in the greenhouse and Ing. Jos Molthoff (PRI-WUR) for his assistance with SYBR-Green analysis. 


\section{References}

Argüello-Morales MA, Remaud-Simeon M, Pizzut S, Sarçabal P, Willemot RM, Monsan P (2000) Sequence analysis of the gene encoding alternansucrase, a sucrase glucosyltransferase from Leuconostoc mesenteroides NRRL B-1355. FEMS Microbiol Lett 182:8185

Argüello-Morales MA, Remaud-Simeon M, Willemot RM, Vignon MR, Monsan P (2001) Novel oligosaccharides synthesized from sucrose donor and cellobiose acceptor by alternansucrase. Carbohydr Res 331:403-411

Cairns AJ (2003) Fructan biosynthesis in transgenic plants. J Exp Bot 54:549-567

Côté GL (1992) Low-viscosity $\alpha$-D-glucan fractions derived from sucrose which are resistant to enzymatic digestion. Carbohydr Polym 19:249-252

Côté GL, Sheng S (2006) Penta-, hexa-, and heptasaccharide acceptor products of alternansucrase. Carbohydr Res 341:2066-2072

Garbarino JE, Belknap WR (1994) Isolation of a ubiquitin-ribosomal protein gene (ubi3) from potato and expression of its promoter in transgenic plants. Plant Mol Biol 24:119-127

Gerrits N (2000) Tuber-specific fructan synthesis in potato amyloplasts. Ph.D. Dissertation, Utrecht University, The Netherlands, ISBN 90-393-2345-3

Gerrits N, Turk SCHJ, van Dun KPM, Hulleman SHD, Visser RGF, Weisbeek PJ, Smeekens SCM (2001) Sucrose metabolism in plastids. Plant Physiol 125:926934

Heilersig HJB (2005) Factors influencing gene silencing of granule-bound starch synthase in potato. Ph.D. Dissertation, Wageningen University, The Netherlands, ISBN 90-8504-247

Hennegan KP, Danna KJ (1998) pBIN20: an improved binary vector for Agrobacterium-mediated transformation. Plant Mol Biol Rep 16:129-131

Janeček S, Svensson B, Russell RRB (2000) Location of repeat elements in glucansucrases of Leuconostoc and Streptococcus species. FEMS Microbiol Lett 192: 5357

Jeanes A, Haynes WC, Wilham CA, Rankin JC, Melvin EH, Austin MJ, Cluskey JE, Fisher BE, Tsuchiya HM, Rist CE (1954) Characterization and classification of dextrans from ninety-six strains of bacteria. $\mathbf{J}$ Am Chem Soc 76:5041-5052

Jobling SA, Westcott RJ, Tayal A, Jeffcoat R, Schwall GP (2002) Production of a freeze-thaw-stable potato starch by antisense inhibition of three starch synthase genes. Nat Biotechnol 20:295-299

Joucla G, Pizzut S, Monsan P, Remaud-Simeon M (2006) Construction of a fully active truncated alternansucrase partially deleted of its carboxy-terminal domain. FEBS Lett 580:763-768

Kok-Jacon GA, Ji Q, Vincken J-P, Visser RGF (2003) Towards a more versatile $\alpha$-glucan biosynthesis in plants. J Plant Physiol 160:765-777
Kok-Jacon GA, Vincken J-P, Suurs LCJM, Wang D, Liu S, Visser RGF (2005a) Production of dextran in transgenic potato plants. Transgenic Res 14:385-395

Kok-Jacon GA, Vincken J-P, Suurs LCJM, Visser RGF (2005b) Mutan produced in potato amyloplasts adheres to starch granules. Plant Biotechnol J 3:341-351

Kuipers AGJ, Jacobsen E, Visser RGF (1994) Formation and deposition of amylose in the potato tuber starch granule are affected by the reduction of granulebound starch synthase gene expression. Plant Cell 6:43-52

Leathers TD, Nunnally MS, Côté GL (2002) Modification of alternan by novel Penicillium spp. J Ind Microbiol Biotechnol 29:177-180

Leathers TD, Nunnally MS, Ahlgren JA, Côté GL (2003) Characterization of a novel modified alternan. Carbohydr Polym 54:107-113

Luz Sanz M, Côté GL, Gibson GR, Rastall RA (2006) Selective fermentation of gentobiose-derived oligosaccharides by human gut bacteria and influence of molecular weight. FEMS Microbiol Ecol 56:383-388

Pilon M, Wienk H, Sips W, de Swaaf M, Talboom I, van 't Hof R, de Korte-Kool G, Demel R, Weisbeek P, de Kruijff B (1995) Functional domains of the ferredoxin transit sequence involved in chloroplast import. J Biol Chem 270:3882-3893

Richard G, Morel S, Willemot RM, Monsan P, RemaudSimeon M (2003) Glucosylation of $\alpha$-butyl- and $\alpha$-octyl-D-glucopyranosides by dextransucrase and alternansucrase from Leuconostoc mesenteroides. Carbohydr Res 338:855-864

Robyt JF (1996) Mechanism and action of glucansucrases. In: Park KH, Robyt JF, Choi TD (eds) Enzymes for carbohydrate engineering. Elsevier, Amsterdam, pp 1-22

Sharon J, Kabat EA, Morrison SL (1982) Immunochemical characterization of binding sites of hybridoma antibodies specific for alpha (1 leads to 6) linked dextran. Mol Immunol 19:375-388

Takken FLW, Luderer R, Gabriëls SHEJ, Westerink N, Lu R, de Wit PJGM, Joosten MHAJ (2000) A functional cloning strategy, based on a binary PVXexpression vector, to isolate HR-inducing cDNAs of plant pathogens. Plant J 24:275-283

Wang D, Liu S, Trummer BJ, Deng C, Wang A (2002) Carbohydrate microarrays for the recognition of cross-reactive molecular markers of microbes and host cells. Nature Biotechnol 20:275-281

Wenzler HC, Mignery A, Fisher LM, Park WD (1989) Analysis of a chimeric class-I patatin-GUS gene in transgenic potato plants: High-level expression in tubers and sucrose-inducible expression in cultured leaf and stem explants. Plant Mol Biol 12:41-50

Wróbel M, Zebrowski J, Szopa J (2004) Polyhydroxybutyrate synthesis in transgenic flax. J Biotechnol 107:41-54 